\title{
PET imaging using radiolabeled antibodies: future direction in tumor diagnosis and correlate applications
}

This article was published in the following Dove Press journal:

Research and Reports in Nuclear Medicine

30 July 2013

Number of times this article has been viewed

\author{
Marco Salsano' \\ Giorgio Treglia ${ }^{2}$ \\ 'Department of Radiology, Catholic \\ University of Rome, Rome, Italy; \\ ${ }^{2}$ Department of Nuclear Medicine, \\ Oncology Institute of Southern \\ Switzerland, Bellinzona, Switzerland
}

\begin{abstract}
Immuno-positron emission tomography (PET) is a new imaging tool that finds application in diagnostic as well as in prognostic and therapeutic oncology. Monoclonal antibodies (mAbs) present the unique ability to selectively bind specific antigens produced by tumors, establishing the presence, location, and number of neoplastic foci. They are produced in unlimited quantities with absolute specificity using the hybridoma method. Treatment with mAbs can have different forms: they can be administered alone or can be combined with a radioactive molecule, which then delivers the radiation directly to the tumor cells. In immuno-PET, mAbs are labeled with various radionuclides and used in cancer patients who produce tumor-associated antigens. In this review we will discuss immuno-PET applications in tumor diseases, focusing on the technique, mAbs, positron emitter selection, and on its future applications.
\end{abstract}

Keywords: Immuno-PET, monoclonal antibodies, radionuclides, radiolabeling

\section{Introduction}

Molecular imaging is one of the most rapidly growing areas of science, and recent developments facilitated the detection of novel molecular targets for tumor cells, principally involved in differentiation, signal transduction and protein interaction networks, cell death and apoptosis, angiogenesis, immune recognition, invasion, proliferation, and metastasis. ${ }^{1}$ Molecular imaging aims to visualize, characterize, and measure processes on molecular and cellular levels in living systems in a noninvasive way. ${ }^{2,3}$ Currently, numerous tracers for imaging cancers by positron emission tomography (PET) have been developed, and the glucose analog, fluorodeoxyglucose (FDG), marked with the radioisotope, fluorine-18 $\left({ }^{18} \mathrm{~F}\right)$, is the most widely used. ${ }^{4}$

${ }^{18} \mathrm{~F}-\mathrm{FDG}$ is injected intravenously and transported into cells by glucose transporter proteins, where it is phosphorylated by hexokinase to form ${ }^{18} \mathrm{~F}-\mathrm{FDG}-6$-phosphate. The cell membrane is impermeable to both glucose-6-phosphate and ${ }^{18} \mathrm{~F}-\mathrm{FDG}-6$ phosphate; however, the latter cannot be further degraded via the glycolysis pathway nor can it easily undergo dephosphorylation by glucose-6-phosphatase. Ultimately, ${ }^{18} \mathrm{~F}$-FDG-6-phosphate remains trapped within the cell in a concentration correlated to cell uptake.

The major issues associated with FDG are nonspecific and elevated uptake in infectious or inflammatory lesions, variable physiological uptake in normal tissues/ organs that may mask the presence of malignant neoplasm, ${ }^{5}$ and the lack of uptake in metabolically inactive malignancy.

Thanks to targeting molecules/ligands that can specifically localize to cellsurface markers such as growth factor receptors, adhesion molecules, and activation
Correspondence: Marco Salsano Department of Radiology, Catholic University of Rome, Largo Gemelli, 8, 00168 Rome, Italy

Email marco.salsano@hotmail.it 
and differentiation markers, it is possible to overcome the limitations of FDG-PET. Identification and validation of novel molecular markers have introduced several new targeted drugs into the clinic.

Molecular imaging agents, denominated tracers or probes, bind specific targets (cell or intracellular surface proteins); these probes are radiolabeled exclusively for PET imaging and offer visualization of physiological and biochemical changes. Conventional imaging modalities like radiography, ultrasonography, computed tomography (CT), in contrast to PET, only offer visualization of nonspecific changes related to morphology.

PET is a highly sensitive functional imaging modality and enables quantitative imaging. ${ }^{6}$ Additionally, technical advances in instrumentation have enabled the combination of morphological and functional information into a single image through fused PET imaging modalities with CT or magnetic resonance imaging (MRI).

Nevertheless, it is unfeasible to control or "switch off" ionizing radiation in vivo because there are no bioavailable materials to quench gamma rays. Therefore, target specificity can be compromised by the high background signals originating from unbound or nonspecifically bound probes.

Monoclonal antibodies (mAbs) are high affinity molecules that can be used for specific, high signal delivery to cell surface molecules, thanks to their strict targeting ability.

The antibody revolution started in 1975 with the introduction of the hybridoma technology by Kohler and Milstein; ${ }^{7}$ with this technology, an unlimited range of mAbs can be obtained against any kind of cellular antigen. The murine origin of the first generations of mAbs made them immunogenic, limiting their clinical use. ${ }^{8,9}$ The production of chimeric $\mathrm{mAb}$, humanized $\mathrm{mAb}$, and complete human $\mathrm{mAb}$ solved this issue.

Today's antibody engineering technologies enable routine production of new, fully human or humanized mAbs (molecular weight $150 \mathrm{kDa}$ ) from display libraries or from immunized transgenic mice carrying human immunoglobulin genes. One may search for the mAb with the best characteristics in binding affinity, blood clearance, and tumor penetration.

To improve the imaging performance, alternative ligands have been developed and extensively studied over the last few years. Among them are antibody fragments and engineered variants such as antigen-binding $\mathrm{F}\left(\mathrm{ab}{ }^{\prime}\right)_{2}$ and F(ab'), singlechain variable fragments ( $\mathrm{scFv}$ ), diabodies, and minibodies (molecular weights ranging from $25-100 \mathrm{kDa}),{ }^{10}$ as well as several types of therapeutic proteins based on nontraditional scaffolds such as domain antibodies, affibodies, nanobodies, and anticalins. ${ }^{11-13}$

These fragments achieve optimal tumor-to-nontumor ratios 1-6 hours after injection, different from intact mAbs that achieve this ratio typically at 2-4 days after injection. Affibodies in particular are very stable and highly water-soluble $\alpha$-helical proteins, with facilitated conjugation chemistry. In particular, the small size, resulting in rapid blood clearance, good tumor penetration, and high binding affinity to selected targets, makes affibody molecules ideal candidates for imaging purposes. Thus far, some mAbs have been approved by the US Food and Drug Administration for cancer therapy, ${ }^{14,15}$ and many are now in experimental phase (Table 1).

Seven of the mAbs have been approved for treatment of hematological malignancies: alemtuzumab, brentuximab vedotin, gemtuzumab ozogamicin, ibritumomab tiuxetan, ofatumumab, rituximab, and tositumomab. Eight mAbs have been approved for therapy of solid tumors: denosumab is used for treatment of bony metastases of solid tumors; trastuzumab, pertuzumab, and ado-trastuzumab emtansine are used for treatment of metastatic breast cancer; bevacizumab, panitumumab, and cetuximab have been approved for treatment of metastatic colorectal cancer; and cetuximab and bevacizumab have also been accepted for the treatment of head and neck cancer and non-small cell lung cancer respectively. Ipilimumab (also known as MDX-101) has been recently approved for treatment of melanoma. Therapy with $\mathrm{mAbs}$ is most effective when combined with chemotherapy or radiotherapy, particularly against solid tumors.

\section{Probe selection}

Taking into account the large number of mAbs directed against new as well as validated targets under development, the question is how to select the best mAbs in an efficient way. The mAbs can act via different mechanisms, such as antibody-dependent cellular cytotoxicity, complementdependent cytotoxicity, induction of apoptosis, or interference with signal transduction pathways by targeting growth factors or their receptors. Once the optimal antibody-based vector has been generated, they should be tagged with radionuclides.

Positron emitters for immune-PET can be classified according to their physical half-life $\left(\mathrm{t}^{1 / 2}\right)$ as short-, intermediate-, and long-living. Their $t^{1} / 2$ should ideally be paired with the biological $t^{1} / 2$ of the antibody fragment. Gallium-68 and ${ }^{18} \mathrm{~F}$ belong to the short-living positron emitters, which are suitable for rapid clearing fragments such as scFv and diabodies. Copper-64 $\left({ }^{64} \mathrm{Cu}\right)$, yttrium-86 $\left({ }^{86} \mathrm{Y}\right)$, 
Table I List of monoclonal antibodies approved by the US Food and Drug Administration and the European Medicines Agency in cancer therapy

\begin{tabular}{|c|c|c|c|c|c|c|c|}
\hline \multirow[t]{2}{*}{ Antibody } & \multirow{2}{*}{$\begin{array}{l}\text { Brand } \\
\text { name }\end{array}$} & \multirow[t]{2}{*}{ Type } & \multirow{2}{*}{$\begin{array}{l}\text { Target: } \\
\text { antibody type }\end{array}$} & \multirow[t]{2}{*}{ Application } & \multirow[t]{2}{*}{ Company } & \multicolumn{2}{|c|}{ Approval year } \\
\hline & & & & & & EU & USA \\
\hline Rituximab & $\begin{array}{l}\text { Rituxan, } \\
\text { MabThera }\end{array}$ & Chimeric IgGI & CD20 & $\begin{array}{l}\text { Non-Hodgkin } \\
\text { lymphoma }\end{array}$ & Genentech & 1998 & 1997 \\
\hline Trastuzumab & Herceptin & Humanized lgGI & HER2 & Breast cancer & Genentech/Roche & 2000 & 1998 \\
\hline $\begin{array}{l}\text { Gemtuzumab } \\
\text { ozogamicin }\end{array}$ & Mylotarg* & $\begin{array}{l}\text { Humanized } \lg G 4, \\
\text { immunotoxin }\end{array}$ & CD33 & $\begin{array}{l}\text { Acute myeloid } \\
\text { leukemia }\end{array}$ & Wyeth/Pfizer & NA & 2000 \\
\hline Alemtuzumab & $\begin{array}{l}\text { MabCampath, } \\
\text { Campath-IH }\end{array}$ & Humanized lgGI & CD52 & $\begin{array}{l}\text { Chronic myeloid } \\
\text { leukemia }\end{array}$ & Genzyme & 2001 & 2001 \\
\hline $\begin{array}{l}\text { Ibritumomab } \\
\text { tiuxetan }\end{array}$ & Zevalin & Murine $\lg \mathrm{I} I$ & CD20 & $\begin{array}{l}\text { Non-Hodgkin } \\
\text { lymphoma }\end{array}$ & Biogen Idec & 2004 & 2002 \\
\hline Tositumomab & Bexxar & Murine $\lg G 2 a$ & CD20 & $\begin{array}{l}\text { Non-Hodgkin } \\
\text { lymphoma }\end{array}$ & Corixa/GSK & NA & 2003 \\
\hline Cetuximab & Erbitux & Chimeric IgGI & EGFR & $\begin{array}{l}\text { Colorectal cancer, } \\
\text { head and neck cancer }\end{array}$ & Imclone/Lilly & 2004 & 2004 \\
\hline Bevacizumab & Avastin & Humanized lgGI & VEGF & $\begin{array}{l}\text { Colorectal cancer, } \\
\text { non-small cell lung } \\
\text { cancer }\end{array}$ & Genentech/Roche & 2005 & 2004 \\
\hline Panitumumab & Vectibix & Human IgG2 & EGFR & Colorectal cancer & Amgen & 2007 & 2006 \\
\hline Ofatumumab & Arzerra & Human IgGI & CD20 & $\begin{array}{l}\text { Chronic lymphocytic } \\
\text { leukemia }\end{array}$ & Genmab & 2010 & 2009 \\
\hline Denosumab & Prolia & Human $\lg G 2$ & RANK ligand & $\begin{array}{l}\text { Bone metastases, } \\
\text { giant cell tumor } \\
\text { of bone }\end{array}$ & Amgen & 2010 & 2010 \\
\hline Ipilimumab & Yervoy & Human IgGI & CTLA-4 & Melanoma & BMS & 2011 & 2011 \\
\hline $\begin{array}{l}\text { Brentuximab } \\
\text { vedotin }\end{array}$ & Adcetris & $\begin{array}{l}\text { Chimeric IgGI, } \\
\text { drug-conjugate }\end{array}$ & CD30 & $\begin{array}{l}\text { Anaplastic large } \\
\text { cell lymphoma, } \\
\text { Hodgkin lymphoma }\end{array}$ & Seattle Genetics & 2012 & 2011 \\
\hline Pertuzumab & Perjeta & Humanized lgGI & HER2 & Breast cancer & Genentech/Roche & 2013 & 2012 \\
\hline $\begin{array}{l}\text { Ado-trastuzumab } \\
\text { emtansine }\end{array}$ & Kadcyla & $\begin{array}{l}\text { Humanized } \lg \mathrm{GI} \text {, } \\
\text { drug-conjugate }\end{array}$ & HER2 & Breast cancer & Genentech/Roche & in review & 2013 \\
\hline
\end{tabular}

Note: *withdrawn in 2010.

Abbreviations: CTLA-4, cytotoxic T-lymphocyte antigen 4; EGFR, epidermal growth factor receptor; HER, human epidermal receptor; NA, not approved; VEGF, vascular endothelial growth factor.

and bromodeoxyuridine-76 are intermediate-living positron emitters, suitable for antibody fragments with intermediate clearance properties such as minibodies and modified scFv- $\mathrm{Fc}$ fragments. Zirconium-89 $\left({ }^{89} \mathrm{Zr}\right)$ and iodine-124 $\left({ }^{124} \mathrm{I}\right)$ are longliving positron emitters, suitable for intact antibodies. ${ }^{16}$

The organic $t^{1} / 2$ of the protein should always be matched with the physical $t^{1} / 2$ of the radionuclide to which it is being conjugated in order to have synchronous activity, even if it does not seem to be fundamental (Table 2); in fact, Colcher et $\mathrm{al}^{17}$ and Nedelman et al ${ }^{18}$ paired long-lasting radionuclides with rapid clearing antibody fragments, producing excellent and high contrast images.

\section{Pharmacokinetics}

Molecular weight, $\mathrm{Fc}$ domains, valency, and specificity influence targeting and pharmacokinetics. The clearness depends principally on weight; larger fragments, above $60 \mathrm{kDa}$, will clear via the liver, whereas those below this size will clear via the kidneys.

The serum residence time can be increased by presence of $\mathrm{Fc}$ domains, consequently raising the exposure time to the target; however, for PET, like for any imaging acquisition, a more rapid clearance from the blood is warranted in order to increase contrast and sensitivity. Localization and accumulation of $\mathrm{mAb}$ in target tissue is related to specificity and avidity, in particular by the number of antigen binding sites, the number of target antigens per cell, and whether it internalizes or not.

Tissue uptake can be low or reduced in some situations, for example when part of the antigen is shaded in the blood, with consequent depletion of the pool of free antibodies available to reach the target, or when the antibody mediate the internalization of the antigen (in this case the rate of antigen internalization is different depending on the antigens). 
Table 2 The physical half-life $\left(t^{1 / 2}\right)$ of the radionuclides used for PET imaging

\begin{tabular}{ll}
\hline Radionuclide & $\mathbf{t} 1 / 2$ \\
${ }^{15} \mathrm{O}$ & 122 seconds \\
${ }^{13} \mathrm{~N}$ & 9.9 minutes \\
${ }^{11} \mathrm{C}$ & 20 minutes \\
${ }^{68} \mathrm{Ga}$ & 68.3 minutes \\
${ }^{18} \mathrm{~F}$ & 110 minutes \\
${ }^{64} \mathrm{Cu}$ & 12.7 hours \\
${ }^{86} \mathrm{Y}$ & 14.7 hours \\
${ }^{76} \mathrm{Br}$ & 16.2 hours \\
${ }^{89} \mathrm{Zr}$ & 78.4 hours \\
${ }^{124} \mathrm{I}$ & 100.3 hours \\
\hline
\end{tabular}

Abbreviations: ${ }^{76} \mathrm{Br}$, bromodeoxyuridine-76; ${ }^{11} \mathrm{C}$, carbon-II; ${ }^{64} \mathrm{Cu}$, copper-64; ${ }^{18} \mathrm{~F}$, fluorine- $18 ;{ }^{68} \mathrm{Ga}$, gallium-68; ${ }^{124} \mathrm{I}$, iodine- $124 ;{ }^{13} \mathrm{~N}$, nitrogen- $13 ;{ }^{15} \mathrm{O}$, oxygen- 15 ; PET, positron emission tomography; ${ }^{86} \mathrm{Y}$, yttrium-86; ${ }^{89} \mathrm{Zr}$, zirconium-89.

Even the nature of label used and the labeling chemistry employed are factors that may affect the targeting.

Cross-reactivity with normal organs can be totally different for xenografted nude mice and cancer patients, even if $\mathrm{mAb}$ reactivity with human tumors is considered to be comparable. This was verified by Cai et al using anti-epidermal growth factor receptor (EGFR) $\mathrm{mAbs}$ in nude mice bearing EGFR (human epidermal receptor 1)-positive human cancer xenografts. ${ }^{19}$ Most EGFR-specific mAbs bind only to human and not to murine EGFR, therefore showing predominantly high and selective tumor uptake. ${ }^{19-21}$

Nonetheless, in another study, an 8-kDa affibody selective to human as well as murine EGFR was evaluated, resulting in a relatively high liver uptake contrasted to the poor tumor uptake. ${ }^{22}$ The results showed that liver uptake was particularly high also after a low affibody dose and could be explained by the abundant EGFR expression in this organ; ${ }^{23}$ this was indicative of the complexity of tumor imaging with a low dose of fast kinetic $\mathrm{mAb}$ fragment when there is a high level of target antigen in well-accessible normal organs.

Another risk to take into consideration is the critical residue modifications that may result in antibody function damage, a condition more frequent as the fragment becomes smaller. That problem can be solved using site-specific conjugation and radiolabeling chemistry.

For clinical trials of new mAbs in human, especially when the $\mathrm{mAb}$ of interest is directed against a novel tumor target that has not been validated in clinical trials before, it is important to evaluate the optimal dose for tumor targeting (eg, saturation of receptors), the uptake in critical normal organs to avoid toxicity, and the interpatient variations in tumor targeting and pharmacokinetics. This information should be provided in an efficient and safe way, trying to treat fewer patients with a suboptimal dose.
Some patients may develop an allergic reaction, especially after the first dose, which can manifest as flu-like symptoms, low blood pressure, shortness of breath, or nausea. For this reason, the first dose is infused slowly over several hours. Before therapy, patients may also take specific drugs to reduce the risk of allergic reaction. Subsequent administration should not create problems.

Finally, only targets with slow internalization rates are suitable to be imaged with radioiodinated $\mathrm{mAbs}$ because of the rapid degradation of the radioactivity that is accumulated in thyroid and hardly excreted by kidneys. ${ }^{24}$ For both diagnostic and therapeutic purposes, all these issues must be taken into consideration before the start of an immunePET exam.

\section{Clinical employment of immuno-PET \\ Clinical immuno-PET}

The quality of labeled mAbs is fundamental to translate immuno-PET from preclinical investigations to a Phase I clinical trial, and a good manufacturing practice is needed to create it. Radionuclides and the chelates used for binding them are to be considered as active pharmaceutical ingredients, especially when the final preparation is released for use without further purification.

Before application, various aspects of the radionuclides must be evaluated: identification (eg, $t^{1} / 2$ and gamma emission spectrum), radiochemical purity, storage conditions, stability data, expiration, batch identification, and impurity profile.

Once high purity of the positron emitter is produced, it is then attached to the targeting vector via a chelating agent, a molecule containing more than one ligand or an atom such as nitrogen, oxygen, or sulfur that can donate a lone pair of electrons. ${ }^{25-27}$ The oxidation state and electronegativity play a major role in the formation of metal-ligand complexes. The chelating agents are customized to provide a way to link them to antibodies and peptides. ${ }^{28}$

New procedures have been established in recent years for assembling a large amount of positron emitters for clinical use, like ${ }^{89} \mathrm{Zr}$, ${ }^{90} \mathrm{Y}$, and ${ }^{124} \mathrm{I} .{ }^{27-31} \mathrm{~A}$ multistep procedure has been developed for stable coupling of ${ }^{89} \mathrm{Zr}$ to $\mathrm{mAbs}$ by Verel et al using a succinylated derivative of desferrioxamine $B$ as a bifunctional chelate. ${ }^{27}$

All reagents and procedures are set to allow broadscale clinical application of immuno-PET with ${ }^{89} \mathrm{Zr}$ - and ${ }^{124} \mathrm{I}$-labeled intact $\mathrm{mAbs} .{ }^{124} \mathrm{I}$ is the radionuclide of choice in combination with noninternalizing mAbs, and ${ }^{89} \mathrm{Zr}$ is particularly suitable for PET imaging of internalizing mAbs 
because it is trapped inside the cell after internalization of the $\mathrm{mAb}$ (residualization). ${ }^{20,32}$ Residualization also occurs to some extent in organs of mAb catabolism such as liver, kidney, and spleen.

After radiolabeling, the reagent undergoes the current Good Manufacturing Practices quality analyses including the assessment of chelate-to-mAb substitution ratio, radiochemical purity, $\mathrm{mAb}$ integrity and immunoreactivity, and apyrogenicity. ${ }^{30,33-35}$

\section{Therapeutic approach}

MAbs have been employed with PET in many applications. They can be used in 1-day imaging ${ }^{25,26}$ to confirm target expression before the start of therapy with intact mAbs. In this approach, short-living (gallium-68, ${ }^{18} \mathrm{~F}$ ) or intermediateliving positron emitters $\left({ }^{64} \mathrm{Cu},{ }^{90} \mathrm{Y}\right.$, bromodeoxyuridine-76) should be used to label mAb fragments or small mAb-like molecules for fast kinetic antibody-based PET probes. ${ }^{36}$

Another therapeutic approach uses long-living positron emitters $\left({ }^{89} \mathrm{Zr},{ }^{124} \mathrm{I}\right)$, labeled directly to therapeutic intact $\mathrm{mAbs}$ for scouting pretherapy setting or, in the early therapy phase, to gain better insight of the in vivo behavior and efficacy of the mAbs in individual patients. Only a fraction of the therapeutic dose of intact $\mathrm{mAb}$ can be radiolabeled, but the injection of cold and radiolabeled $\mathrm{mAb}$ should occur simultaneously or immediately after each other; in this way, relation between targeting efficiency and therapeutic response can be studied..$^{37}$ MAbs can be labeled to radionuclide with short-range ( $\alpha$ - or $\beta$-particles) emissions for what is called radioimmunotherapy (RIT). ${ }^{38}$

The purpose of RIT is to maximize the absorbed dose to target volumes, while ensuring delivery to susceptible normal organs within acceptable limits; generally the doselimiting organ is the red marrow (ie, the blood-forming cells). A prerequisite for this approach is that PET radioimmunoconjugates and RIT radioimmunoconjugates must show a similar biodistribution.

Bone marrow is usually dose-limiting for RIT, and individualized imaged-based dosimetry is probably required for the optimal therapeutic delivery of radiolabeled antibodies, which must not compromise red marrow and may allow, for some patients, a substantial increase in administered activity and thus tumor dose.

PET can provide quantitative, three-dimensional images that may be used to study biochemical and physiologic processes in the human body like $\gamma$-camera-based singlephoton emission computed tomography. ${ }^{39,40}$ The advantage of PET is a more accurate attenuation correction that enables calibration of the scanner in terms of the absolute activity concentration in a tissue (ie, $\mathrm{Bq} / \mathrm{mL}$ ); this is of fundamental importance in accurately determining radiation doses to tissues or organs. In addition, PET, in clinical practice, provides higher sensitivity and spatial resolution than single-photon emission computed tomography or planar $\gamma$-camera imaging. Long-living positron emitters are needed for this plan to successfully image antibody biodistribution over time scales of a week or more after administration. ${ }^{41,42}$

Immune-PET can be applied also for prognosis prediction or for reducing false negative receptor expression, as shown by Capala and Bouchelouche in the case of human epidermal receptor 2 (HER2). ${ }^{43}$ HER2 overexpression is correlated with aggressive tumor behavior and poor clinical outcome. Therefore, HER2 has become an important prognostic and predictive factor as well as a target for molecular therapies.

Because of the heterogeneity of breast cancer and possible discordance in HER2 status between primary tumors and distant metastases, assessment of HER2 expression by noninvasive imaging may become an important complement to immunohistochemistry or fluorescence in situ hybridization analyses of biopsied tissue. Monoclonal antibodies such as trastuzumab and pertuzumab, or small scaffold proteins such as affibody molecules, are used as HER2-targeting agents, providing information on HER2 expression not only in primary tumors but also in distant metastases not amenable to biopsy; that may reduce problems with false negative results and, thereby, influence patient management by selecting patients that would benefit from HER2-targeted therapies. $^{44,45}$

All these individualized approaches to cancer treatment rely on multimodality imaging to help clinicians in selecting a proper therapy and to monitor its efficacy at early stage in order to eventually adjust the treatment. The noninvasive character of molecular imaging allow repeating the test serially in individual patients and, thereby, provide "real-time" data on early tumor response that could be used to optimize the dosage of the effective drugs or discontinue ineffective treatment before the tumor recurs. ${ }^{43}$

\section{Dual-labeled mAbs for PET and fluorescence molecular imaging} In the last few years, PET and near-infrared fluorescence (NIRF) imaging have been merged in some studies with the intention to improve sensitivity and accuracy in imaging. Paudyal et al were the first to publish a demonstration of a multimodal $\mathrm{mAb}$ agent that utilizes the PET platform for imaging CD20 lymphoma in mice. ${ }^{46}$ Anti-CD20 mAbs is the 
basis in the treatment of non-Hodgkin's lymphomas and have shown efficacy in patients with B-cell chronic lymphocytic leukemia. The authors used an anti-CD20 murine mAb for targeting CD20-positive tumors labeled with ${ }^{64} \mathrm{Cu}$ through the use of 1,4,7,10-tetraazacyclododecane-1,4,7,10-tetraacetic acid (DOTA) as the bifunctional chelating agent, along with Alexa Fluor 750, a NIRF dye. They showed that ${ }^{64} \mathrm{Cu}$-DOTANuB2-Alexa Fluor 750 exhibits strong and specific binding to the tumor-expressing CD20 antigen through ex vivo biodistribution and in vivo PET and NIRF imaging. In addition, they demonstrated a statistically significant correlation between radioactivity and fluorescence intensity, confirming the stability of the dual functional probe.

Another example of a dual-labeled mAb used for PET was given by Sampath et al, who developed a dual-labeled analog of trastuzumab for PET/NIRF imaging to detect metastatic breast cancer. ${ }^{47}$ The authors conjugated the $\mathrm{mAb}$ to ${ }^{64} \mathrm{Cu}$-DOTA and IRDye $800 \mathrm{CW}$ (a specific dye), showing excellent tumor localization and quantification of tracer uptake in local and metastatic sites.

Further use of PET imaging for multimodal probe development was shown in patients with prostate cancer, using mAbs specific for epithelial cell adhesion molecule to prevent metastases in patients diagnosed with various cancers ${ }^{48}$ and useful for the detection of circulating tumor cells. ${ }^{49-51}$ In a study by Hall et al, the same dual-labeled mAbs were used to provide both intraoperative and noninvasive imaging of cancer-positive lymph nodes in an orthotopic model of metastatic human prostate cancer. ${ }^{52}$

Although the performance of planar imaging is not directly comparable to tomographic imaging, NIRF planar imaging showed greater sensitivity and specificity for tumorpositive lesions than PET imaging. These results nonetheless provided evidence of the added utility that planar NIRF imaging could provide to nuclear imaging modalities.

Especially in intraoperative guidance, dual-labeled agents hold promise for whole-body and intraoperative imaging and could bridge the gap between surgical planning and imageguided resection with a single, molecularly targeted agent. This technique may allow a single targeting portion to be used throughout the patient care process in all phases: diagnosis, staging, treatment planning, surgical guidance, therapeutic monitoring, and validation of histological findings. ${ }^{53}$

\section{PET/MRI}

MRI is a powerful imaging modality with regard to high spatial resolution and tomographic capabilities, but the low signal sensitivity has been a major limitation for molecular imaging. The advantage of hybrid PET/MRI system using radiomarked mAbs depends on its ability to provide MR images that are spatially coincident with simultaneously acquired PET images, allowing combined morpho-functional MRI and PET studies of intratissue heterogeneity. In a recent study conducted by $\mathrm{Ng}$ et al, the ability of a first-generation, small-animal MRI-compatible PET scanner was evaluated to accurately depict heterogeneous patterns of ${ }^{64} \mathrm{Cu}$-labeled antibody uptake in tumors. ${ }^{54}$ The PET/MRI scanner showed a stable and linear response; the tumor images were quantitatively accurate and spatially concordant with autoradiography and the small-animal PET examination, confirming the ability of the current simultaneous PET/MRI system to provide accurate observations of intratumoral function.

MRI has been presented as a technique able to show $\mathrm{mAb}$ localization, as described by Lee et al; the recent development and the increased sensitivity of magnetismengineered iron oxide nanoprobes obtained when conjugated to Herceptin may make antibody fragments attractive MRI imaging agents. ${ }^{55}$

Whole-body MRI has been reported to show excellent diagnostic performance by itself, and is proposed as an alternative to or replacement for PET/CT ${ }^{56,57}$ Combining the metabolic data of PET with the morphologic and functional information provided by MRI may further improve the diagnostic value of each method alone. Although the literature is still limited, data indicate a potential advantage of PET/ MRI over PET/CT. ${ }^{58,59}$

\section{State of art and future perspectives}

High sensitivity, adequate spatial resolution, and proven quantification abilities makes PET the modality of choice for applying molecular imaging in the clinical setting. PET is actually the most specific and accurate method for tumor localization and has allowed significant improvements in radiation dose estimation. It offers a millimetric magnitude of spatial resolution ( $5 \mathrm{~mm}$ or lower for new generation timeof-flight scanners), resolves the problem of different tissue overlapping, better defines heterogeneous uptakes, gives three-dimensional representations of patient-specific distributions of tracer, and can boast the use of a positron-emitting radioisotope from the same element of therapeutic ones, such as the matched pairs ${ }^{124} \mathrm{I} /{ }^{131} \mathrm{I}$ or ${ }^{86} \mathrm{Y} /{ }^{90} \mathrm{Y}$. Exact dosimetry can be difficult to perform in radionuclide therapy as compared to external beam radiation therapy; however, in hybrid imaging systems with CT and PET in the same scanning session which combine patient anatomy and tracer distribution, it 
is possible to use Monte Carlo radiation transport codes to calculate patient-specific 3-dimensional dose. ${ }^{14}$

New PET/MRI technology bears the potential to repeat the success of PET/CT, particularly for oncologic indications. We think MRI will add new useful functional information to the PET exam, without missing the morphological data already provided currently by $\mathrm{PET} / \mathrm{CT}$, and ultimately reduce the patient radiation exposure.

Whether PET/MRI will replace PET/CT or be a complementary methodology remains to be evaluated, while also taking into account economic considerations. The development of new technologies has a great impact in health care, and this concept is particularly true for high technology disciplines like nuclear medicine and immunology.

The antibody-based imaging for determining the molecular "phenotype" of tumors and tissues in a noninvasive way can play an important role in the development, evaluation, and implementation of molecularly targeted therapeutics. It can also aid in initial tumor detection, while simultaneously providing information regarding the tissue of origin or biological potential of the lesion. To achieve high tumor uptake and tumor-to-blood ratios, which will result in highcontrast images, the properties of the targeting molecule and radionuclide, the type of target, and the desirable imaging time point must be considered collectively.

With the current advances in biotherapeutics and antibody-directed drug delivery systems, it becomes fundamental to be able to screen patients prior to specific antibody therapies, and to design patient-tailored therapeutic regimens, thereby avoiding unnecessary toxicities. ${ }^{60}$ Radiolabeled antibodies function as carriers of cytotoxic substances, such as radioisotopes for treatment of cancer; they have superior antitumor activity compared with their unconjugated antibody counterparts, but there is increased, albeit manageable, hematological toxicity if the careful pretreatment planning and dosimetry is performed. ${ }^{61,62}$ However, renal and bone marrow radiation toxicity are a primary concern, therefore careful pretreatment dosimetry and screening is required, especially in patients under chemotherapy. ${ }^{31,63}$

Image and treatment strategy can bring about consistency and lead to better outcomes of cancer treatment. The major issue of this approach in clinical practice is the limited number of clinical trials testing the predictive and prognostic value of a tumor's receptor expression assessed by molecular imaging. This question is perhaps connected to the lack of interest of pharmaceutical companies in molecular imaging agents. This situation might be changed if the drug regulatory agencies required a combination of molecular targeting agents with appropriate imaging probes to verify their efficacy.

A review of the literature clearly shows that improvement is being made in the preclinical setting, but that translation to the clinic continues to be slow. With recent developments in radionuclide production and accessibility, as well as improved radiolabeling methods, movement of immuno-PET imaging agents into the clinical setting should be accelerated. ${ }^{26}$

In the next years, immuno-PET will facilitate the therapeutic use of radiopharmaceuticals, showing the targeting of the molecule and predicting dosimetry. New generation PET/CT scanners, characterized by high resolution and high sensitivity, allow for the production of high-quality images of biological processes to predict biodistribution and to calculate dosimetric data. The availability of "new" radionuclides and new technology to link them, not only to antibodies but also to peptides or other molecules, is going to be of great benefit for the diagnosis and treatment of various tumors.

We believe immuno-PET will be utilized as a scouting procedure before RIT, aiming to confirm tumor targeting and accurately estimating radiation dose delivery to both tumor and normal tissues and might therefore be of value for selection of patient candidates for RIT.

On the other hand, the development of new specific antibodies is fundamental to reach more kinds of tumors and more histotypes for the same tumor. In this way, the treatment or diagnostic procedure will be evermore specific to the patient pathology. All this work must be coordinated with radiopharmaceutical licensing, which is becoming more strictly regulated and complicated.

In the future, working toward medical multidisciplinary collaboration, physicians, radiopharmacists, oncologists, physicists, and technologists will work with cooperation in contributing to nuclear medicine and immunology for developing new techniques of radiolabeling and new specific antibodies. In this context, PET will expand its role from a diagnostic tool to an imaging tool, able to characterize each single patient in order to provide the best treatment available.

The advances in specific receptor imaging may be a step toward a new "image and treat" strategy, not only in the cancer field but also in infective pathology ${ }^{64-67}$ and in degenerative diseases, principally to study amyloid deposits in primary amyloidosis. ${ }^{68-70}$

The nuclear medicine community must work together as well as with national authorities and industry to promote the distribution of radiopharmaceuticals for molecular imaging and molecular therapy. ${ }^{71}$ 
Immuno-PET imaging will surely continue to advance, involving new disciplines and addressing different pathologies. Immuno-PET is expected to improve the characterization, diagnosis, and immunotherapy of tumors, but many more studies are required to prepare and evaluate positron-emitter labeled antibodies.

\section{Disclosure}

The authors report no conflicts of interest in this work.

\section{References}

1. Hanahan D, Weinberg RA. The hallmarks of cancer. Cell. 2000;100(1): $57-70$.

2. Cai W, Chen X. Multimodality molecular imaging of tumor angiogenesis. J Nucl Med. 2008;49(Suppl 2):113S-128S.

3. Bogdanov A, Weissleder R. In vivo imaging of gene delivery and expression. Trends Biotech. 2002;20(8):S11-S18.

4. Gillings N. Radiotracers for positron emission tomography imaging. MAGMA. 2013;26:149-158

5. Shreve PD, Anzai Y, Wahl RL. Pitfalls in oncologic diagnosis with FDG PET imaging: physiologic and benign variants. Radiographics. 1999;19(1):61-77; quiz 150.

6. Massoud TF, Gambhir SS. Molecular imaging in living subjects: seeing fundamental biological processes in a new light. Genes Dev. 2003;17(5): $545-580$.

7. Mistretta VI, Cavalier E, Collette J, Chapelle JP. Production of monoclonal antibodies. Rev Med Liege. 2009;64(5-6):248-252. French.

8. Bernett MJ, Karki S, Moore GL, et al. Engineering fully human monoclonal antibodies from murine variable regions. J Mol Biol. 2010;396(5): 1474-1490.

9. DeNardo GL, Bradt BM, Mirick GR, DeNardo S. Human antiglobulin response to foreign antibodies: therapeutic benefit? Cancer Immunol Immunother. 2003;52(5):309-316.

10. Demarest SJ, Glaser SM. Antibody therapeutics, antibody engineering, and the merits of protein stability. Curr Opin Drug Discov Devel. 2008;11(5):675-687.

11. Villani ME, Morea V, Consalvi V, et al. Humanization of a highly stable single-chain antibody by structure-based antigen-binding site grafting. Mol Immunol. 2008;45(9):2474-2485.

12. Nord K, Gunneriusson E, Ringdahl J, Ståhl S, Uhlén M, Nygren PA. Binding proteins selected from combinatorial libraries of an alpha-helical bacterial receptor domain. Nat Biotechnol. 1997;15(8): $772-777$.

13. Roovers RC, van Dongen GA, van Bergen en Henegouwen PM. Nanobodies in therapeutic applications. Curr Opin Mol Ther. 2007;9(4): 327-335.

14. Waldmann TA. Immunotherapy: past, present and future. Nat Med. 2003;9(3):269-277.

15. Antibodysociety.org [homepage on the Internet]. Waban, Massachusetts: The Antibody Society; 2007 [Updated March 10, 2013]. Available from: http://www.antibodysociety.org/news/approved_mabs.php/. Accessed April 13, 2013.

16. Deri MA, Zeglis BM, Francesconi LC, Lewis JS. PET imaging with ${ }^{89} \mathrm{Zr}$ : from radiochemistry to the clinic. Nucl Med Biol. 2013;40(1): 3-14.

17. Colcher D, Bird R, Roselli M, et al. In vivo tumor targeting of a recombinant single-chain antigen-binding protein. J Natl Cancer Inst. 1990;82(14):1191-1197.

18. Nedelman MA, Shealy DJ, Boulin R, et al. Rapid infarct imaging with a technetium-99 m-labeled antimyosin recombinant single-chain Fv: evaluation in a canine model of acute myocardial infarction. $J$ Nucl Med. 1993;34(2):234-241.
19. Cai W, Chen K, He L, Cao Q, Koong A, Chen X. Quantitative PET of EGFR expression in xenograft-bearing mice using $64 \mathrm{Cu}$-labeled cetuximab, a chimeric anti-EGFR monoclonal antibody. Eur J Nucl Med Mol Imaging. 2007;34(6):850-858.

20. Perk LR, Visser GW, Vosjan MJ, et al. (89)Zr as a PET surrogate radioisotope for scouting biodistribution of the therapeutic radiometals $(90) \mathrm{Y}$ and (177) Lu in tumor-bearing nude mice after coupling to the internalizing antibody cetuximab. J Nucl Med. 2005;46(11):1898-1906.

21. Aerts HJ, Dubois L, Perk L, et al. Disparity between in vivo EGFR expression and 89Zr-labeled cetuximab uptake assessed with PET. J Nucl Med. 2009;50(1):123-131.

22. Tolmachev V, Friedman M, Sandström M, et al. Affibody molecules for epidermal growth factor receptor targeting in vivo: aspects of dimerization and labeling chemistry. $J$ Nucl Med. 2009;50(2):274-283.

23. Collin de L'hortet A, Gilgenkrantz H, Guidotti JE. EGFR: a master piece in $\mathrm{G} 1 / \mathrm{S}$ phase transition of liver regeneration. Int J Hepatol. Epub September 23, 2012.

24. Olafsen T, Wu AM. Antibody vectors for imaging. Semin Nucl Med. 2010;40(3):167-181

25. Verel I, Visser GW, van Dongen GA. The promise of immuno-PET in radioimmunotherapy. $J$ Nucl Med. 2005;46(Suppl 1):164S-171S.

26. McCabe KE, Wu AM. Positive progress in immunoPET - not just a coincidence. Cancer Biother Radiopharm. 2010;25(3):253-261.

27. Verel I, Visser GW, Boellaard R, Stigter-van Walsum M, Snow GB, van Dongen GA. 89Zr immuno-PET: comprehensive procedures for the production of $89 \mathrm{Zr}$-labeled monoclonal antibodies. $J$ Nucl Med. 2003;44(8):1271-1281.

28. Brechbiel MW, Gansow OA. Backbone-substituted DTPA ligands for 90Y radioimmunotherapy. Bioconjug Chem. 1991;2(3):187-194.

29. Holland JP, Sheh Y, Lewis JS. Standardized methods for the production of high specific-activity zirconium-89. Nucl Med Biol. 2009;36(7): 729-739.

30. Tijink BM, Perk LR, Budde M, et al. (124)I-L19-SIP for immunoPET imaging of tumour vasculature and guidance of (131)I-L19-SIP radioimmunotherapy. Eur J Nucl Med Mol Imaging. 2009;36(8): $1235-1244$.

31. Nayak TK, Brechbiel MW. $86 \mathrm{Y}$ based PET radiopharmaceuticals: radiochemistry and biological applications. Med Chem. 2011;7(5): 380-388.

32. Verel I, Visser GW, Boerman OC, et al. Long-lived positron emitters zirconium-89 and iodine-124 for scouting of therapeutic radioimmunoconjugates with PET. Cancer Biother Radiopharm. 2003;18(4): 655-661.

33. Perk LR, Visser OJ, Stigter-van Walsum M, et al. Preparation and evaluation of (89)Zr-Zevalin for monitoring of (90)Y-Zevalin biodistribution with positron emission tomography. Eur J Nucl Med Mol Imaging. 2006;33(11):1337-1345.

34. Verel I, Visser GW, Vosjan MJ, Finn R, Boellaard R, van Dongen GA. High-quality 124I-labelled monoclonal antibodies for use as PET scouting agents prior to 131I-radioimmunotherapy. Eur J Nucl Med Mol Imaging. 2004;31(12):1645-1652.

35. Verel I, Visser GW, Boellaard R, et al. Quantitative 89Zr immuno-PET for in vivo scouting of $90 \mathrm{Y}$-labeled monoclonal antibodies in xenograftbearing nude mice. J Nucl Med. 2003;44(10):1663-1670.

36. Achmad A, Hanaoka H, Yoshioka H, et al. Predicting cetuximab accumulation in KRAS wild-type and KRAS mutant colorectal cancer using $64 \mathrm{Cu}$-labeled cetuximab positron emission tomography. Cancer Sci. 2012;103(3):600-605.

37. Börjesson PK, Jauw YW, de Bree R, et al. Radiation dosimetry of 89Zr-labeled chimeric monoclonal antibody U36 as used for immunoPET in head and neck cancer patients. $J$ Nucl Med. 2009;50(11): $1828-1836$.

38. O'Donoghue JA, Smith-Jones PM, Humm JL, et al. 124I-huA33 antibody uptake is driven by A33 antigen concentration in tissues from colorectal cancer patients imaged by immuno-PET. $J$ Nucl Med. 2011;52(12):1878-1885. 
39. Phelps ME. PET: the merging of biology and imaging into molecular imaging. J Nucl Med. 2000;41(4):661-681.

40. Phelps ME. Positron emission tomography provides molecular imaging of biological processes. Proc Natl Acad Sci U S A. 2000;97(16): 9226-9233.

41. Divgi CR, Pandit-Taskar N, Jungbluth AA, et al. Preoperative characterisation of clear-cell renal carcinoma using iodine-124-labelled antibody chimeric G250 (124I-cG250) and PET in patients with renal masses: a phase I trial. Lancet Oncol. 2007;8(4):304-310.

42. Carrasquillo JA, Pandit-Taskar N, O’Donoghue JA, et al. (124) I-huA33 antibody PET of colorectal cancer. J Nucl Med. 2011;52(8): 1173-1180.

43. Capala J, Bouchelouche K. Molecular imaging of HER2-positive breast cancer: a step toward an individualized 'image and treat' strategy. Curr Opin Oncol. 2010;22(6):559-566.

44. van Dongen GA, Visser GW, Lub-de Hooge MN, de Vries EG, Perk LR. Immuno-PET: a navigator in monoclonal antibody development and applications. Oncologist. 2007;12(12):1379-1389.

45. van Dongen GA, Vosjan MJ. Immuno-positron emission tomography: shedding light on clinical antibody therapy. Cancer Biother Radiopharm. 2010;25(4):375-385.

46. Paudyal P, Paudyal B, Iida Y, et al. Dual functional molecular imaging probe targeting CD20 with PET and optical imaging. Oncol Rep. 2009;22(1):115-119.

47. Sampath L, Kwon S, Hall MA, Price RE, Sevick-Muraca EM. Detection of cancer metastases with a dual-labeled near-infrared/positron emission tomography imaging agent. Transl Oncol. 2010;3(5):307-317.

48. Baeuerle PA, Gires O. EpCAM (CD326) finding its role in cancer. Br J Cancer. 2007;96(3):417-423.

49. Das DK. Serous effusions in malignant lymphomas: a review. Diagn Cytopathol. 2006;34(5):335-347.

50. Nagrath S, Sequist LV, Maheswaran S, et al. Isolation of rare circulating tumour cells in cancer patients by microchip technology. Nature. 2007;450(7173):1235-1239.

51. Ntouroupi TG, Ashraf SQ, McGregor SB, et al. Detection of circulating tumour cells in peripheral blood with an automated scanning fluorescence microscope. Br J Cancer. 2008;99(5):789-795.

52. Hall MA, Kwon $\mathrm{S}$, Robinson $\mathrm{H}$, et al. Imaging prostate cancer lymph node metastases with a multimodality contrast agent. Prostate. 2012;72(2):129-146.

53. Azhdarinia A, Ghosh P, Ghosh S, Wilganowski N, Sevick-Muraca EM. Dual-labeling strategies for nuclear and fluorescence molecular imaging: a review and analysis. Mol Imaging Biol. 2012;14(3):261-276.

54. Ng TS, Bading JR, Park R, et al. Quantitative, simultaneous PET/MRI for intratumoral imaging with an MRI-compatible PET scanner. J Nucl Med. 2012;53(7):1102-1109.

55. Lee JH, Huh YM, Jun YW, et al. Artificially engineered magnetic nanoparticles for ultra-sensitive molecular imaging. Nat Med. 2007;13(1):95-99.
56. Picchio M, Ratib O. PET/MRI. Clin Transl Imaging. 2013;1:3-4.

57. Ratib O. PET/MRI: a new era in multimodality molecular imaging. Clin Transl Imaging. 2013;1:5-10.

58. Ziegler SI, Delso G. Technical and methodological aspects of PET/MR. Clin Transl Imaging. 2013;1:11-16.

59. Pace L, Nicolai E, Aiello M, Catalano OA, Salvatore M. Whole-body PET/MRI in oncology: current status and clinical applications. Clin Transl Imaging. 2013;1:31-44.

60. Zhou Y, Baidoo KE, Brechbiel MW. Mapping biological behaviors by application of longer-lived positron emitting radionuclides. Adv Drug Deliv Rev. Epub November 2, 2012.

61. Wiseman GA, White CA, Stabin M, et al. Phase I/II 90Y-Zevalin (yttrium-90 ibritumomab tiuxetan, IDEC-Y2B8) radioimmunotherapy dosimetry results in relapsed or refractory non-Hodgkin's lymphoma. Eur J Nucl Med. 2000;27(7):766-777.

62. Wiseman GA, White CA, Witzig TE, et al. Radioimmunotherapy of relapsed non-Hodgkin's lymphoma with zevalin, a 90Y-labeled anti-CD20 monoclonal antibody. Clin Cancer Res. 1999;5(Suppl 10): 3281s-3286s.

63. Bodei L, Cremonesi M, Ferrari M, et al. Long-term evaluation of renal toxicity after peptide receptor radionuclide therapy with $90 \mathrm{Y}$ DOTATOC and 177 Lu-DOTATATE: The role of associated risk factors. Eur J Nucl Med Mol Imag. 2008;35(10):1847-1856.

64. Bray M, Di Mascio M, de Kok-Mercado F, Mollura DJ, Jagoda E. Radiolabeled antiviral drugs and antibodies as virus-specific imaging probes. Antiviral Res. 2010;88(2):129-142.

65. Di Mascio M, Srinivasula S, Bhattacharjee A, et al. Antiretroviral tissue kinetics: in vivo imaging using positron emission tomography. Antimicrob Agents Chemother. 2009;53(10):4086-4095.

66. Hatori A, Arai T, Yanamoto K, et al. Biodistribution and metabolism of the anti-influenza drug [11C]oseltamivir and its active metabolite [11C]Ro 64-0802 in mice. Nucl Med Biol. 2009;36(1):47-55.

67. Konno F, Arai T, Zhang MR, et al. Radiosyntheses of two positron emission tomography probes: [11C]oseltamivir and its active metabolite [11C]Ro 64-0802. Bioorg Med Chem Lett. 2008;18(4):1260-1263.

68. Solomon A, Weiss DT, Wall JS. Immunotherapy in systemic primary (AL) amyloidosis using amyloid-reactive monoclonal antibodies. Cancer Biother Radiopharm. 2003;18(6):853-860.

69. Wall JS, Paulus MJ, Gleason S, Gregor J, Solomon A, Kennel SJ. Micro-imaging of amyloid in mice. Meth Enzymol. 2006;412: $161-182$.

70. Wall JS, Kennel SJ, Stuckey AC, et al. Radioimmunodetection of amyloid deposits in patients with AL amyloidosis. Blood. 2010;116(13): 2241-2244.

71. Lopci E, Chiti A, Castellani MR, et al. Matched pairs dosimetry: 124I/131I metaiodobenzylguanidine and 124I/131I and 86Y/90Y antibodies. Eur J Nucl Med Mol Imaging. 2011;38(Suppl 1): S28-S40.
Research and Reports in Nuclear Medicine

\section{Publish your work in this journal}

Research and Reports in Nuclear Medicine is an international, peerreviewed, open access journal publishing original research, reports, reviews and commentaries on all areas of nuclear medicine. The manuscript management system is completely online and includes a very

\section{Dovepress}

quick and fair peer-review system. Visit http://www.dovepress.com/ testimonials.php to read real quotes from published authors. 